Revista Internacional de Apoyo a la Inclusión, Logopedia, Sociedad y Multiculturalidad.

Volumen 6, Número 1, enero 2020, ISSN: 2387-0907. DOI: https://doi.org/10.17561/riai.v6.n1.05

\title{
A importância da participação da família no processo de ensino-aprendizagem.
}

The importance of family participation in the teaching-learning process.

\author{
Andréia Lobo Moreira de Lima \\ Universidade Tecnológica Intercontinental (UTIC) (Paraguay) \\ andreia-sinop@hotmail.com
}

Fecha recepción: 12/10/2019

Páginas 49-61

Fecha aceptación: 25/12/2019

\section{Resumo.}

Neste artigo desenvolvemos uma investigação sobre a importância da participação da família na comunidade escolar, e sua relação no processo de ensino aprendizagem. Dessa forma, buscamos como objetivo geral analisar a participação da família no processo de ensino-aprendizagem e sua relação no processo ensino-aprendizagem. Para os objetivos específicos procuramos identificar a política da instituição, com relação à participação dos pais nas atividades curriculares e extracurriculares, e também, identificar as consequências da participação e da não participação dos pais no aspecto educacional, motivacional e econômico no processo de ensinoaprendizagem de seus filhos. Esta pesquisa realizou-se na Escola Estadual "Edeli Mantovani", Sinop (Brasil). Utilizamos uma metodologia quantitativa, com desenho não experimental com característica descritiva. Para a coleta de dados utilizamos questionário ao gestor escolar, a coordenação pedagógica, educadores e pais. Por tanto, verificamos que se torna necessário a participação da família na escola para que aconteça aprendizagem no processo de ensino aprendizagem.

Palavras Chaves: educação; participação; família; ensino-aprendizagem; política educativa

\section{Abstract.}

In this article we develop an investigation on the importance of family participation in the school community, and its relationship in the teaching-learning process. Thus, we aim to analyze the family participation in the teaching-learning process and its relationship in the teaching-learning process. For specific purposes we seek to identify the institution's policy regarding parental participation in curricular and extracurricular activities, and also to identify the consequences of parental participation and nonparticipation in educational, motivational and economic aspects in the teaching-learning process. of your kids. This research was conducted at Edeli Mantovani State School, Sinop (Brazil). We used a quantitative methodology, with non-experimental design with descriptive characteristic. For data collection we used a questionnaire to the school manager, the pedagogical coordination, educators and parents. Therefore, we verified 
that it is necessary the participation of the family in school for learning to happen in the teaching-learning process.

Keywords: education; participation; family; teaching and learning; educational policy

\section{1.-Introdução.}

Segundo o Piletti (1999) a influência familiar nos primeiros anos de vida, pode contribuir para 0 desenvolvimento de uma personalidade mais agressiva conforme modelo e elementos comportamentais que receber da família. A aprendizagem da criança na atualidade está muito distante daquela em que se podia aprender todo 0 necessário sem sair de asa. Atualmente, ela necessita de toda a informação a que tenha acesso, tanto de maneira informal quanto formal.

Diante deste quadro, o estudo destaca a importância quando os pais participam na vida escolar dos seus filhos, participando dos eventos os quais são desenvolvidos pela escola.

Buscamos desenvolver este estudo nas escolas de $1^{\circ} \mathrm{Ano}$ do Ensino Médio no período matutino, buscando assim, ponderar a participação dos pais nas atividades escolares. Acompanhar a educação dos filhos é uma tarefa difícil e complexa, porém, na maioria das vezes, agradável, pois permite aos pais acompanhar seu crescimento físico, intelectual e emocional. Os pais podem e devem procurar a melhor maneira de se relacionar com cada um de seus filhos, pois quanto mais sabemos como nossos filhos são, mais facilmente poderemos reconhecer mudanças significativas em seu comportamento que possam indicar algum tipo de dificuldade.

A importância de se fazer a pesquisa em relação à participação da família no processo de ensino aprendizagem é que possa auxiliar a compreender como se dá 0 desenvolvimento escolar dos alunos, para que se possa melhorar o processo de aprendizagem dos mesmos.

\section{2.-Família.}

Diversos são os conceitos para definir família, os quais podemos simplificar como uma organização social. O termo "família" deriva do latim, significa casa, e foi criado pelos romanos, o qual caracterizou o surgimento da família patriarcal, onde a mulher, os filhos e certo número de escravos submetiam-se ao poder paterno de seu chefe, que detinha o direito de vida e da morte sob todos (Train, 1997, p. 62).

De acordo com Tiba (2014) a família é o primeiro contato social da criança logo ao nascer, é a responsável pela inserção social em outros contextos. A família é um pequeno grupo social composto por indivíduos relacionados uns aos outros em razão de fortes lealdades e afetos recíprocos, ou seja, a família tem sido, no decorrer da história da humanidade, a célula-mãe da sociedade, aquela que prepara os indivíduos para conviver em grupo, exercendo influência na sua formação (Tiba, 2014, p. 43).

Os modelos de família, hoje, se diferenciam e muito dos modelos de décadas passadas, são arranjadas e estruturadas de diferentes maneiras, ligadas ou não por vínculos parentais e afetivos, constitui-se por diferentes pessoas, com diferentes papéis. Para Soares (2004), as experiências educacionais vivenciadas pelas crianças 
nos primeiros anos de sua vida, especialmente em relação aos seus pais irão fornecer subsídios para a constituição de sua personalidade, e por tanto, o desenvolvimento social da criança se dá em diferentes fases numa perspectiva de desenvolvente harmônico dos aspectos físico, ajuste psicológico e social. (Soares, 2004, p.122).

\section{1.-Educação.}

Segundo Piaget, a autonomia não está relacionada com isolamento (capacidade de aprender sozinho e respeito ao ritmo próprio - escola comportamentista), na verdade temos que florescer do pensamento autônomo e lógico operatório em paralelo ao surgimento da capacidade de estabelecer relações cooperativas. E a educação nesse sentido é fator fundamental para desenvolver no aluno características de personalidade marcante capaz de sobreviver na sociedade atual. "Esta personalidade é baseada pela estrutura das atividades do sujeito" com seu vínculo com o mundo. Sendo formada, pelo pensar, sentir e fazer (Piaget,1999, p.32).

E desta forma, o reconhecimento da educação se estrutura em função da formação de conceitos e valores internalizados da cultura, sendo produto da ação educativa entre sujeitos e entre gerações. O reconhecimento do aluno no contexto escolar pode ser facilitado pela compreensão que se tenha de suas motivações e interesses. De forma que, a escola sempre foi titulada como responsável pelo conhecimento, considerada 0 único lugar que garante efetivamente a relação de cidadania. A Lei de Diretrizes e Bases da Educação (LDB 9394/96) somada a produção de conhecimento relativo ao desenvolvimento e à aprendizagem das crianças é que houve as efetivas mudanças, tanto na gestão quanto no discurso e na pratica pedagógica. E por tanto, a educação, dada sua complexidade e crescente ampliação, já não é vista como responsabilidade exclusiva da escola, mas sim responsabilidade de todos os envolvidos inclusive da família. E neste processo o professor tem papel fundamental pois, sua função é conduzir a classe, apesar da resistência de muitos alunos, que o estão testando ao conhecimento, obter a atenção, desempenho, criatividade.

\section{2.-Educação e família.}

As mudanças na educação são visíveis no que diz respeito às práticas educacionais, o qual entende que uma escola democrática define-se pela participação do alunado e do professorado no trabalho, na convivência, e nas atividades de integração. E neste aspecto, a família tem passado por grandes transformações ao longo dos anos. No século $X X$, houve um maior acesso das crianças à escola, concomitantemente. $E$ nesse sentido, a família torna responsável por educar e preparar o indivíduo para a convivência em sociedade, processo este que de concretiza no âmbito escolar.

A educação tem um valor cultivado historicamente pelo homem e, portanto, um conteúdo cultural que precisa ser apropriado pelas novas gerações, por meio do processo educativo. De acordo com Vigotsky (2007) o aprendizado das crianças começa muito antes de elas frequentarem a escola." (p.94), por tanto, cabe à escola 
construir um espaço de diálogo e respeito, onde todos se sintam involucrados. Pois esta condição encarrega a educação sistematizada, a efetivar e possibilitar uma aprendizagem significativa. Por isso é que não tem sentido a alegação de que, se o aluno não quer aprender, não cabe à escola a responsabilidade por seu fracasso" (Vigotsky, 2007, p.14).

Assim, a família e a escola são alicerces para qualquer indivíduo, por isso essa aproximação fará não somente com que a escola cumpra seu papel de socializadora de conhecimento, mas também resultará na motivação dos alunos, além de ser um bom caminho para que a escola atinja seu objetivo de formar cidadãos responsáveis e conscientes de seu papel na sociedade. Portanto, torna-se imprescindível estabelecer uma relação de parceria entre a escola e a família, os resultados no desempenho escolar dos alunos resultarão tanto no escolar como no social.

\section{3.-A importância da participação da família no processo de Ensino- aprendizagem.}

A participação da família no processo de ensino e aprendizagem influi na qualidade de ensino e no desempenho dos alunos. A família precisa estar em torno da escola e ter uma participação ativa, pois, a interação entre escola e comunidade é de suma importância para o estabelecimento de mecanismos de negociação de normas e regras dentro da escola e na sociedade.

Dessa forma, destacamos que educar significa preparar o aluno para a vida, pois a educação é necessária para que todas as pessoas tenham uma participação efetiva na sociedade independente da sua condição social, econômica, religiosa de forma igualitária. No entanto, cabe a escola o papel de auxiliar nesse processo para a formação desse indivíduo para que possa se transformar e compreender a concepção de homem e de mundo.

E neste aspecto, requer novos métodos de ensino, novos currículos, novas práticas educacionais com aspectos inovadores e reforçar os valores sociais, onde educando e educadores participam do processo de uma nova realidade, pois no campo de conhecimentos em construção é que se desenvolve este processo educacional, na prática cotidiana.

Por tanto, quando falamos do processo de ensino e aprendizagem é necessário que 0 professor favoreça a participação dos alunos, com conteúdo que venham a desenvolver a interação em sala de aula, contando sempre com a presença do professor, que exercerá o papel de orientador em suas dificuldades. E neste sentido, "a aprendizagem é um processo individual que consiste em mudanças permanentes", que se integram ao comportamento do indivíduo, levando-o a agir diferentemente em situações novas posteriores. (Pinheiro e Gonçalves, 1997, p. 09).

Nos últimos anos, o sistema educacional brasileiro tem mudado para responder às exigências do mercado, da sociedade e do indivíduo. Para Rodrigues (2000), a educação escolar não pode ser pensada como algo neutro em relação ao mundo, mas como algo que produz na sua própria dinâmica, caminhos diferenciados para ação social concreta em função de interesses e necessidades do próprio educando. 
A educação escolar torna-se cada vez mais indispensável aos cidadãos, as exigências do mercado de trabalho aumentam seguindo as transformações da sociedade, 0 avanço progressivo da ação do estado no campo da educação, e a atuação religiosa tem se reduzido progressivamente e o estado moderno toma para si a responsabilidade do plano educacional. Então a educação surgiu através da necessidade que o homem tinha para compreender o mundo e principalmente para compreender o seu semelhante (Rodrigues, 2000, p.56).

De acordo com a UNESCO (2019), uma das principais organizações que defende os interesses em relação à educação, afirma que "A educação do homem moderno é considerada em numerosos países, como um problema de grande seriedade com dificuldades socio políticas, e, em todos sem exceção, como uma tarefa da mais alta importância". É um tema capital, de envergadura universal, para todos os homens que se preocupam em melhorar o mundo de hoje e preparar o de amanhã (UNESCO, 2019, p. 06).

\section{1.-O Processo de Ensino e Aprendizagem no Brasil.}

O ensino no Brasil foi introduzido pelos missionários Jesuítas, da Companhia de Jesus de Portugal em 1534 sob a chefia do Padre Manuel da Nóbrega e acompanhado pelo então $1^{\circ}$ Governador Geral, Tomé de Souza. Durante mais de 30 anos, os Jesuítas foram os únicos educadores da colônia, fundando colégios em vários pontos do litoral e no interior com a educação ministrada segundo os moldes europeus e voltada para a religião. $O$ ensino nessa época foi considerado com um fator de distinção de classes, pois aos indígenas, a tarefa educativa limitava-se à catequese.

A presença Jesuítica servia aos interesses econômicos e políticos da Coroa, pois não contribuía para uma modificação na estrutura de vida social e econômica da colônia, tendo em vista que não havia um padrão escolar brasileiro e sim uma cópia da educação europeia.

Em 1759, os Jesuítas foram expulsos do Brasil, por ordem do Marquês de Pombal. E foram instituídas "aulas régias", dirigidas por professores leigos, e assim, o ensino entrou na fase da decadência até o século XIX. E conforme a história com a chegada da família real, o sistema educacional no Brasil sofreu severas modificações. Estas serviram para mudar a realidade local e dar início a um avanço a nível de educativo social e econômico do País. Por tanto, os primeiros vinte e cinco anos, nada diferem dos últimos tempos de Império. Somente em 1930 é criado o Ministério da Educação e Saúde Pública, com o intuito de acalmar os setores do estado a nível econômico e também a nível educacional. Desde então, e até hoje, diagnósticos, denúncias e propostas de educação popular têm estado sempre presentes nos discursos políticos em relação à educação pública, principalmente ao que refere a ensino e aprendizagem.

Neste contexto de abandono, a educação pública continua agonizando e a qualidade do ensino vem caindo dia após dia. A educação, deste modo, é a mediação entre teoria e prática. Porque "consideramos que a educação da classe dominada não se dá na escola. Más sim, que a escola dos dominantes dá os instrumentos necessários para reprodução desta classe" e como esta relação é também dialética ao mesmo tempo 
que estes instrumentos contribuem para reproduzir a classe, eles também podem ser úteis na sua luta contra a mesma (De Barros, Hernández, p.69).

A Constituição Federal de 1988, o sistema educacional brasileiro passou por um processo de modificação. Em seu Artigo 208, inciso IV, determina que o dever do Estado

A atual Lei de Diretrizes e Bases da Educação Nacional (LDB n ${ }^{\circ}$ 9394/96) que alterou e realizou mudanças na organização do sistema escolar, tanto no âmbito nacional quanto municipal, e somente após a publicação da Lei de Diretrizes e Bases da Educação (LDB 9394/96) somada a produção de conhecimento relativo ao desenvolvimento e à aprendizagem das crianças é que houve as efetivas mudanças, tanto na gestão quanto no discurso e na pratica pedagógica.

Neste aspecto, Piaget (1999), aclara a ideia sobre o processo de desenvolvimento da personalidade sendo único e individual que abrange estágios que acontecem de acordo com sua teoria da psicogenética, que a construção da autonomia representa um princípio fundamental, que deve nortear todo o processo educativo, desde 0 primeiro contato com a criança com a escola e o saber transmitido ao longo da história e a influência familiar como início socioeducativo (Piaget, 1999, p.33) .

\section{4.-Marco metodológico.}

Realizamos uma pesquisa descritiva, explicativa do tipo não experimental, porque 0 investigador somente observa o fenômeno ou variáveis que já ocorreu, sem intervenção do mesmo. 0 processo descritivo visa à identificação, registro e análise das características, fatores ou variáveis que se relacionam com o fenômeno ou processo. E na pesquisa explicativa registra fatos, analisa-os, interpreta-os e identifica suas causas. Essa prática visa ampliar generalizações, definir leis mais amplas, estruturar e definir modelos teóricos, relacionar hipóteses em uma visão mais unitária do universo ou âmbito produtivo em geral e gerar hipóteses ou ideias por força de dedução lógica (Lakatos, 2017, p. 52).

Em nossa investigação utilizamos o enfoque quantitativo, onde o foco principal da pesquisa são os entrevistados, o qual realizamos a aplicação de uma entrevista ao gestor escolar, coordenadores pedagógicos, e professores do $1^{\circ}$ ano do Ensino Médio. Também aplicamos aos educandos do $1^{\circ}$ ano do Ensino médio e seus respectivos pais da Escola Estadual Professora Edeli Mantovani em Sinop-MT, Brasil, no que tange a participação dos pais no processo de ensino-aprendizagem dos educandos. De acordo com Hernández Sampieri (2019), na abordagem quantitativa é o mais utilizado nas ciências exatas ou naturais, "devido a usar a coleta de dados para comprovar hipóteses, com base em medição numéricas e análises estatísticas, para estabelecer padrões de comportamento e provar teorias"(Hernández Sampieri, 2019, p.25).

Nossa população é de 105 profissionais, no qual, temos 1.658 alunos no total, e constituímos nossa amostra de forma intencional por: de 01 (um) gestor escolar, 04 (quatro) coordenadores pedagógicos, 04 (quatro) educadores das disciplinas do $1^{\circ}$ ano do Ensino Médio período matutino, 30 (trinta) educandos e seus 30 (trinta) respectivos 
pais. O critério de seleção utilizado para a seleção da amostra foi "pertence ao $1^{\circ}$ ano do Ensino Médio, período da manhã".

Para a coleta de dados utilizamos utilizados instrumentos como as entrevistas, ao gestor escolar, coordenadores pedagógicos, docentes dos alunos do $1^{\circ}$ ano do EM, e pais dos mesmos que estudam no $1^{\circ}$ ano do E.M da Escola Estadual Professora Edeli Mantovani, entrevista construída de acordo com os objetivos específicos e validados por juízo de especialistas para aplicação das perguntas de investigação.

Para análise dos dados, em um primeiro momento realizamos uma revisão bibliográfica, com novas leituras com o objetivo de ampliar o conhecimento sobre a Participação da Família na Escola. Em seguida sobre as entrevistas aplicadas, as recolhemos para organizar a descrição do marco analítico da pesquisa.

\section{5.-Análises e descrição dos dados.}

Em nossas análises de dados detalhamos as repostas, mas relevantes da pesquisa:

Gráfico. -1- De acordo a percepção da família obtivemos:

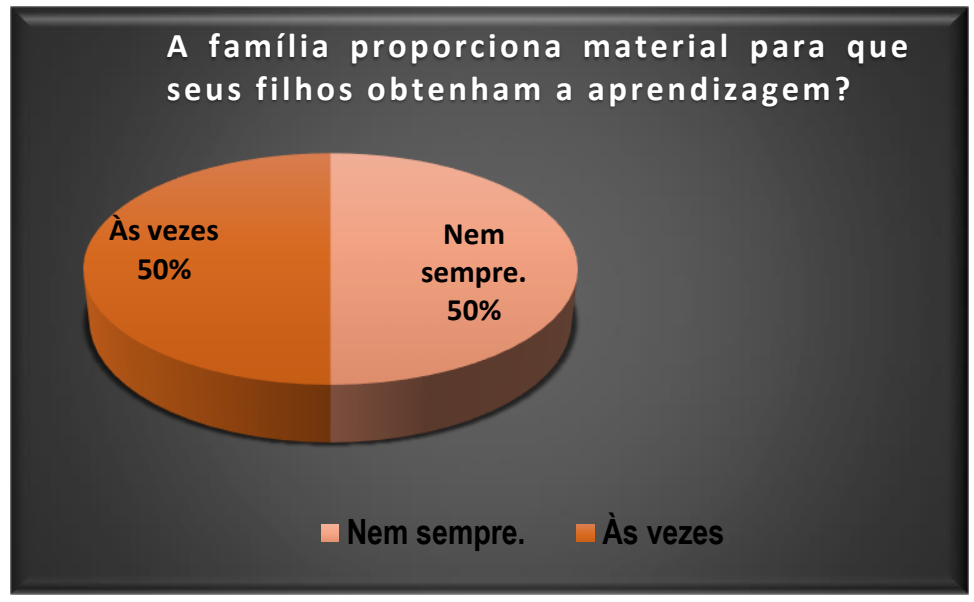

Fonte própria.

Conforme demostra no gráfico acima, a família entende que os materiais educativos são de responsabilidade conjunta para que aconteça a aprendizagem significativa. $\mathrm{Ou}$ seja, tivemos um $50 \%$ de acordo com a família que nem sempre proporciona os materiais adequados e são conscientes desse ato, como também, entendem que sua importância. Tivemos um $50 \%$ as vezes proporcionam os materiais que auxiliam a aprendizagem na escola que nos demostra que compreendem que para seus filhos aprendam tem que ter os materiais adequados e necessários para proporcionar a aprendizagem significativa. Dessa forma, a família entende que os materiais educativos são fatores que possibilita e fortalece a aprendizagem. Portanto, vale enfatizar que Família e Escola, são as estruturas de referência essencial para 0 
processo de aprendizagem. E nesse sentido, pensamos estes são as bases sociais da necessidade de colaboração e o compromisso compartilhado esta responsabilidade e compromisso entre a família e a escola como agentes privilegiados da educação para que aconteça essa aprendizagem significativa.

Gráfico. -2- De acordo a percepção da família obtivemos:

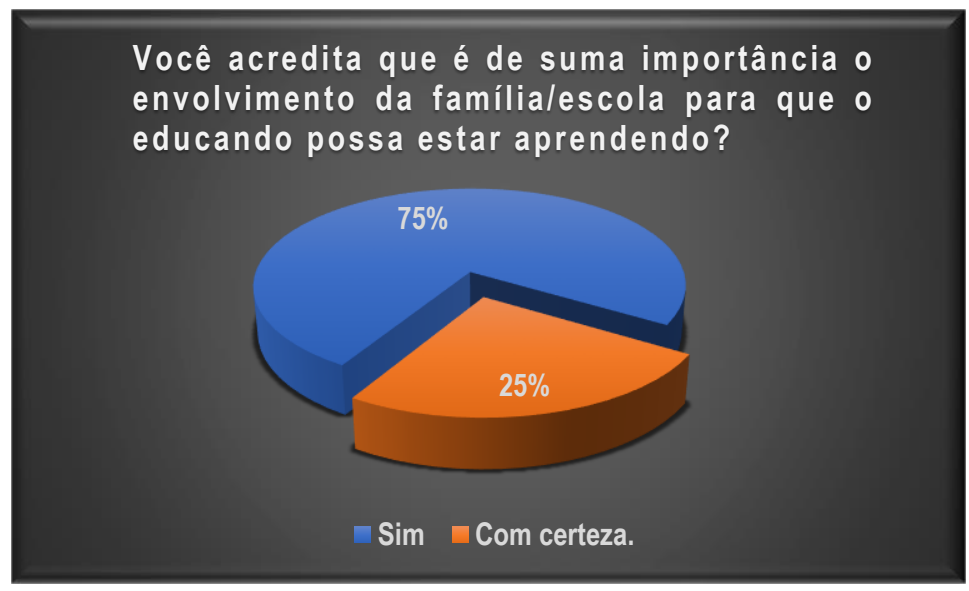

Fonte própria.

Quando perguntamos sobre a importância de haver um a melhor envolvimento da família na escola para que o aluno tenha uma melhor aprendizagem, tivemos $25 \%$ com certeza e um $15 \%$ que sim, onde foram relativamente desproporcionais, porque um $75 \%$ acreditam que sim que esta é de suma importância para a aprendizagem.

Gráfico. -3- De acordo aos professores tivemos: 
Revista Internacional de Apoyo a la Inclusión, Logopedia, Sociedad y Multiculturalidad. Volumen 6, Número 1, enero 2020, ISSN: 2387-0907. DOI: https://doi.org/10.17561/riai.v6.n1.5

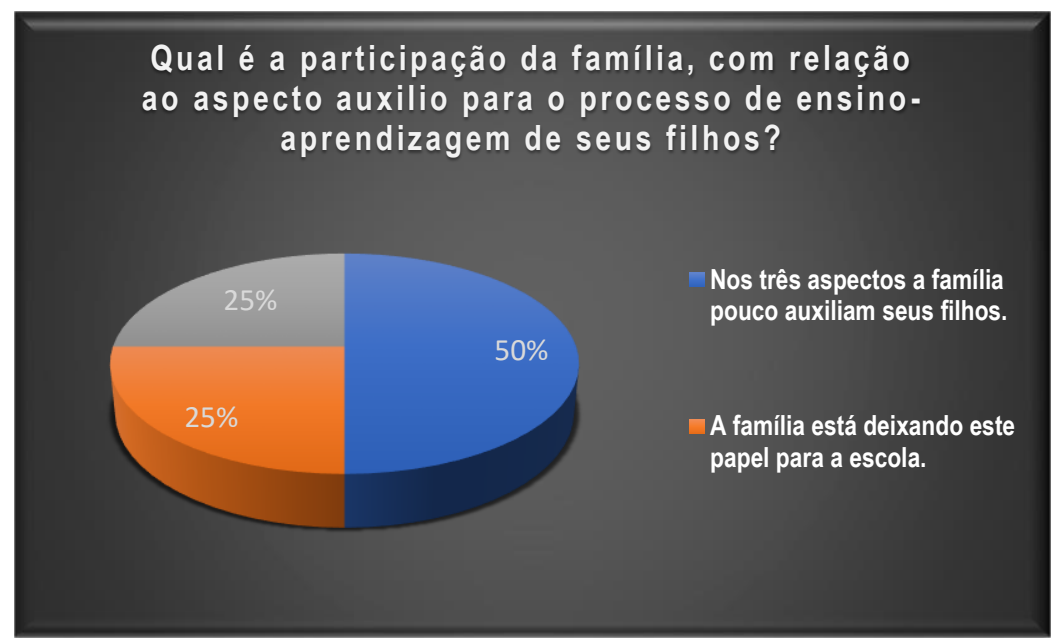

Fonte própria.

De acordo com o gráfico acima quando perguntamos sobre ao auxílio da família tivemos a maioria das pospostas que estão de acordo que a família pouco contribuem quanto ao aspecto no processo de ensino e aprendizagem.

Gráfico. - 4- De acordo aos diretores escolares obtivemos:

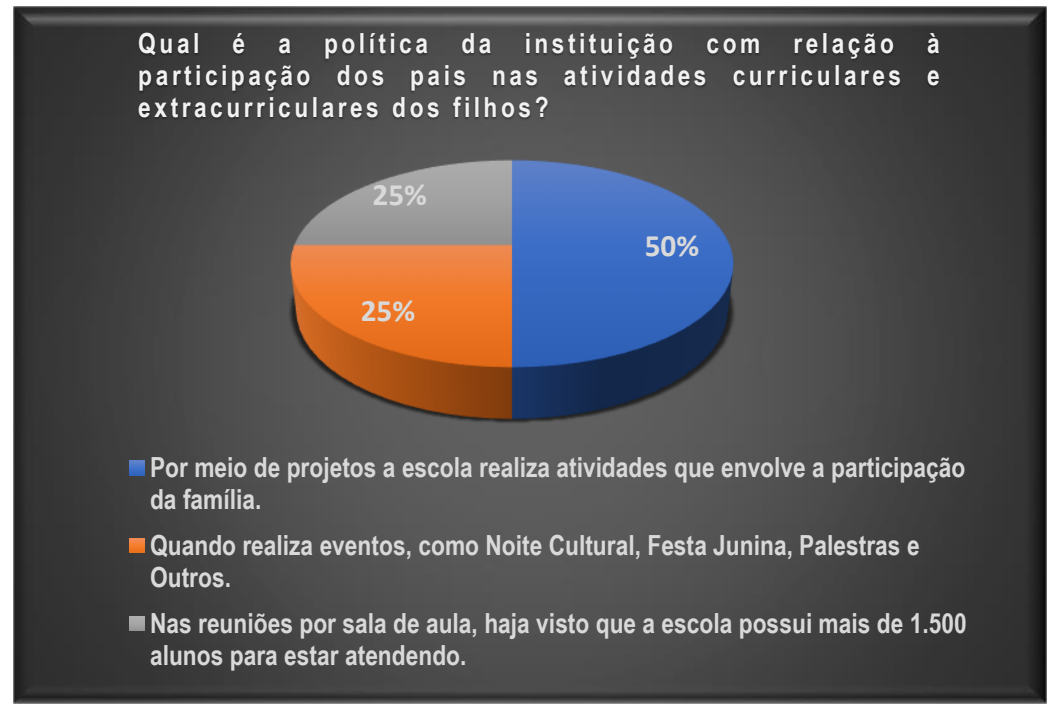

Fonte própria. 
Quando perguntado sobre a política da instituição como acontece a participação da família, obtivemos uma grande maioria que entende que é por meio de projetos da escola, onde realiza atividades que envolve a participação da família.

Gráfico. -5- De acordo com aos alunos obtivemos:

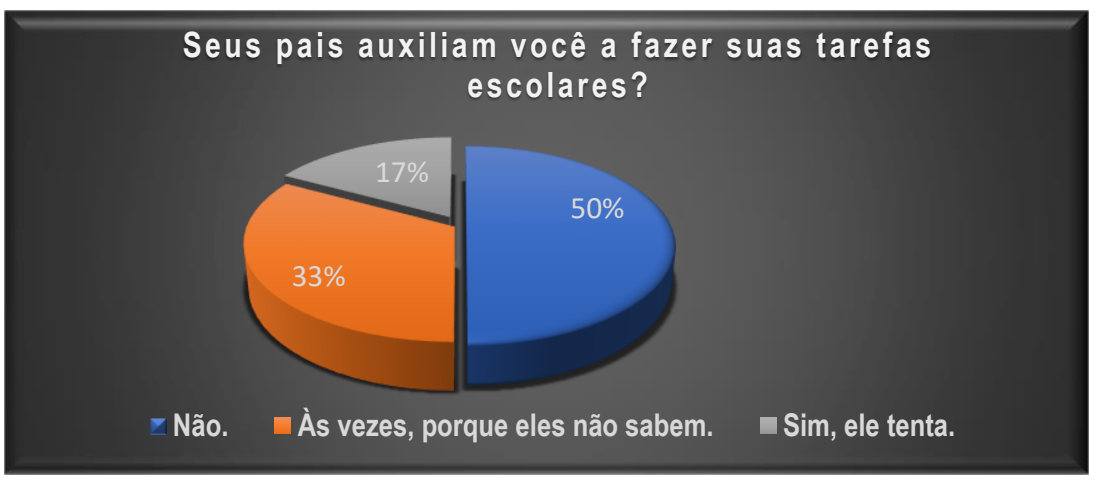

Fonte própria.

Quando perguntamos aos alunos sobre as dificuldades escolares e para realizar as tarefas obtivemos um $50 \%$ os seus pais não auxiliam nas tarefas escolares, onde isso dificulta mais a aprendizagem.

Gráfico. -6- De acordo com aos alunos obtivemos:

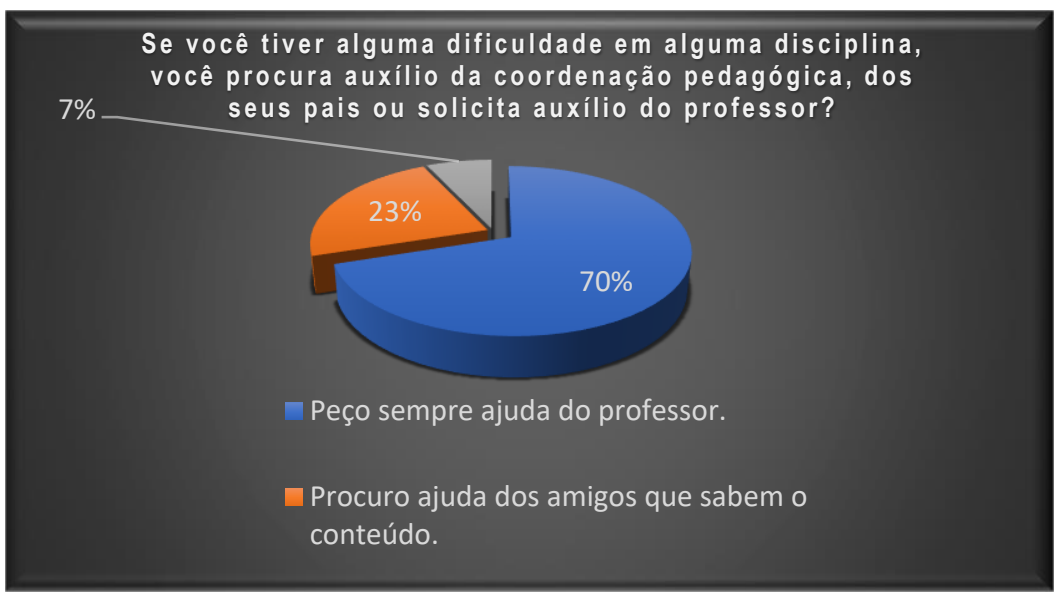

Fonte própria.

Neste aspecto, uma grande maioria afirma solicitar a ajuda do professor onde tivemos $70 \%$ dos participantes que afirmam pedir ajuda do professor. E neste sentido, uma pequena quantidade busca outros auxilio. Onde $25 \%$ procura ajuda dos amigos que entendem 0 conteúdo. $\mathrm{O}$ que nos surpreende é que apenas um $7 \%$ solicita ajuda dos pais. 
Gráfico. -7- Quando investigamos aos coordenadores:

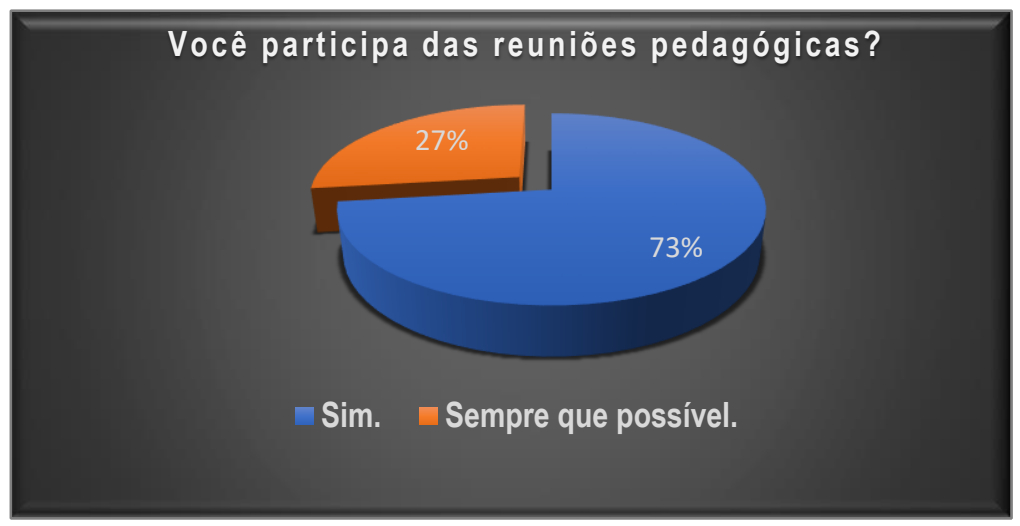

Fonte própria.

Quando perguntamos aos coordenadores se eles participam das reuniões pedagógicas, $73 \%$ participam, sendo uma grande maioria. E apenas $27 \%$ nos confirmam que sempre que possível, ou seja, essa pequena maioria não compreende que este é um processo importante e deve ser contínuo.

\section{6.-Conclusão.}

Nos dias atuais há uma necessidade da escola em estar em sintonia com a família. A escola é uma instituição que complementa a família e juntas tornam-se lugares agradáveis para a convivência e aprendizagem dos alunos. De acordo com as respostas obtidas em nossa investigação compreendemos que tem uma diferença nos resultados buscamos responder aos objetivos específicos e ao objetivo geral e em sequência o problema de investigação para concluir nosso trabalho de investigação.

Para comprovar nossos adjetivos específicos buscamos determinar a participação da família, com relação ao aspecto educacional, motivacional e econômico no processo de ensino-aprendizagem e percebemos que uma grande maioria acredita que sim que este é de suma importância para a aprendizagem.

Por outra parte, procuramos identificar a política da instituição, com relação à participação dos pais nas atividades curriculares e extracurriculares, percebemos que compreendem a necessidade más confirmam que nem sempre atendem como deveriam atendê-los para que haja uma aprendizagem significativa. Buscamos também, identificar as consequências da participação e da não participação dos pais no aspecto educacional, motivacional e econômico no processo de ensinoaprendizagem de seus filhos. E neste aspecto os participantes nos revelaram que os pais devem acompanhar o desempenho escolar, com responsabilidade e sempre que possível intermediar esta aprendizagem. E verificamos o quarto objetivo de que maneira a família participa do processo de ensino aprendizagem dos filhos, onde os participantes nos revelaram que 50\% pensam que é dever da escola, e outros $50 \%$ que seu dever da família, ou seja, existe uma divisão de opiniões relativo a esta 
temática. E buscando a responder o quinto objetivo específico de que maneira a família controla as tarefas escolares de seus filhos, percebemos com as respostas que uma grande maioria não realiza este controle. No referido e último objetivo específico buscar a identificar se a escola possui em seu quadro administrativo professores capacitados para estarem atuando em sala de aula, e detectamos que eles entendem a necessidade e solicitam uma formação continuada, pois este é o início de uma nova forma de educar com formação adequada e atuação proporcional para desenvolver uma aprendizagem significativa. E de acordo com os dados identificamos que o gestor e os coordenadores pedagógicos devem ser um elo entre a família e escola. $E$ de acordo as respostas nos revelaram que compreendem que os pais e os educandos devem estar mais conectados para que haja um processo de aprendizagem.

Dessa forma, em relação ao nosso objetivo geral que buscamos analisar a importância da participação da família no cotidiano escolar no processo de ensino-aprendizagem, detectamos que, os pais dos educandos devem estar mais atentos para o que haja uma aprendizagem. Ou seja, os pais devem frequentar mais vezes a escola, devem verificar as tarefas escolares dos seus filhos, ajudá-los e contribuir para a aprendizagem e de certa forma estar más presente nesse processo educativo sempre que for necessário, pois o aluno necessita desse acompanhamento, e que este seja algo constante comprovamos então que há uma necessidade de um melhor envolvimento família e escola.

Concluímos que com a participação dos pais mais frequentes na escola é possível que os alunos desenvolvam habilidades e competências imprescindível para seu desenvolvimento social e educacional. $E$ este acompanhamento possibilita uma autonomia pessoal, com formação significativa e mais humana. Assim, a escola como responsável pela formação social e educativa tem participação importante neste processo. E deve estar proporcionando maneiras solucionar as dificuldades dos educandos que não conseguiram atingir os objetivos propostos educativos, juntamente em parceria entre família e escola. E de maneira que todos possam estar desempenhando suas funções para que atinjam o objetivo proposto que é formar 0 educando em todos os âmbitos. A participação da família impulsiona o processo de ensino-aprendizagem, e para isso, é importante a participação de todos. Onde é necessário usar metodologias que envolvam o estudante no processo, tornando-o participante ativo e contando com à participação dos pais e de toda a comunidade escolar.

\section{7.-Bibliografia.}

Ainscow, M. (2019). Developing Inclusive Schools: Implications for leadership. Nottingham: Nationa.

De Barros, C., Hernández, A. (2018). Educación Inclusiva. Bases neurocientíficas y Tecnológicas e inclusión y Transculturalidad. Jaén: Masquelibros, S.L. 
Hernández, Sampieri, A., Baptista, M.P., Fernández, C. (2019). Metodología de la investigación: las rutas cuantitativa, cualitativa y mixta. México: Interamericana.

Lakatos, E.M., Mariana, A.M. (2017). Metodologia Científica. São Paulo: Atlas.

Oliveira, D., Rosar, M. (2002). Política e gestão da educação. Belo Horizonte: Autêntica Editora.

Perrenoud, P. (1996). As competências para ensinar no século XXI. Porto Alegre: Artmed.

Silvares, E., De Mattos, F. (2000). Estudos de casos em psicologia clínica comportamental infantil. Campinas/SP: Papirus.

Tiba, I. (2002). Quem ama educa. São Paulo: Gente.

Wallon, H. (1975). Psicologia e educação da infância. Lisboa: Estampa. 